REVISTA X, Curitiba, volume 14, n.6,p.66-86, 2019.

\title{
UM OLHAR INTERACIONISTA SOCIODISCURSIVO SOBRE UM PROGRAMA DE ENSINO DE LÍNGUAS ESTRANGEIRAS PARA INTERNACIONALIZAÇÃO
}

\begin{abstract}
A Socio-Discursive Interactionist Perspective at a Foreign Languages Teaching Program Aimed at Internationalization
\end{abstract}

Cibele CORADIN-BAIL (UEL) ${ }^{1}$

\begin{abstract}
RESUMO: Ações de políticas linguísticas voltadas para comunidades acadêmicas universitárias de todo o país vêm recebendo crescente atenção na última década. No Paraná, o programa Paraná Fala Idiomas (PFI) tem ofertado cursos de línguas estrangeiras a alunos, docentes e agentes universitários das Instituições de Ensino Superior (IES) estaduais desde 2013. Os benefícios potenciais esperados com o programa parecem estar explicitamente voltados para o processo de internacionalização das IES envolvidas. Neste artigo, busco identificar, sob uma perspectiva interacionista sociodiscursiva (BRONCKART, 1999; BRONCKART; MACHADO, 2004), as razões e finalidades para a criação do programa explicitadas no texto de apresentação divulgado no website oficial da Superintendência Geral de Ciência, Tecnologia e Ensino Superior (SETI), bem como os papéis atribuídos a cada protagonista encontrado no discurso analisado. A análise permite constatar que a internacionalização das IES do Paraná se faz presente tanto no plano motivacional quanto no plano da intencionalidade do programa O Paraná Fala Idiomas.
\end{abstract}

PALAVRAS-CHAVE: Internacionalização; Mobilidade internacional; Paraná Fala Idiomas; Políticas linguísticas.

\begin{abstract}
Language policies dedicated to academic communities in universities throughout the country have received increasing attention in the past decade. In Parana, the Parana Speaks Languages program has offered foreign language courses to students, professors and university staff of Higher Education Institutions (HEIs) of the state since 2013. The potential benefits expected from the program seem to be explicitly aimed at the process of internationalization of the HEIs involved. In this work, I seek to identify, under a socio-discursive interactionist perspective (BRONCKART, 1999; BRONCKART; MACHADO, 2004), the reasons and purposes for the creation of the program explicit in the text that present it, found in the official website of SETI (General Oversight of Science, Technology and Higher Education), as well as the roles attributed to each protagonist mentioned in the text. The analysis leads to the conclusion that the internationalization of the HEIs in Parana is present both in the scope of motivation and in the scope of intentionality of the Parana Speaks Languages program.
\end{abstract}

KEYWORDS: Internationalization; International mobility; Language policies; Parana Speaks Languages.

\footnotetext{
${ }^{1}$ Licenciada em Letras Inglês pela Universidade Federal do Paraná (UFPR) e Mestranda em Estudos da Linguagem pela Universidade Estadual de Londrina (UEL). cibelebail@gmail.com
} 


\section{CONSIDERAÇÕES INICIAIS}

Na última década, o Brasil tem sido palco de crescentes esforços em busca da internacionalização de suas Instituições de Ensino Superior (IES), acarretando maior interesse por parte de professores e estudantes universitários pelo desenvolvimento de competências linguísticas em idiomas estrangeiros. Duas razões, em especial, parecem exercer papel central nesse processo. De um lado, a demanda, para pesquisadores, de programas de mobilidade acadêmica no exterior, os quais requerem, naturalmente, competências linguísticas no idioma alvo para que os participantes apresentem um bom rendimento em suas atividades. De outro, a busca pela inserção das universidades brasileiras no cenário internacional da pesquisa por meio da produção e disseminação do conhecimento local. É a partir dessa conjuntura que surge um novo cenário, voltado para o aperfeiçoamento de competências linguísticas das comunidades acadêmicas de diversas universidades do país. (SARMENTO; ABREU-E-LIMA; MORAES FILHO, 2016).

Por meio de ações de políticas linguísticas, o Brasil tem presenciado o surgimento de diversos programas, nos últimos anos, tanto a nível nacional quanto estadual, com vistas a preparar linguisticamente estudantes e professores dos cursos de graduação e pós-graduação para o processo de internacionalização das universidades brasileiras. Um importante exemplo dessas iniciativas é o programa Idiomas sem Fronteiras $^{2}$, instituído em 2012 pelo governo federal, tendo ofertado mais de 350.000 vagas em cursos de línguas estrangerias até novembro de $2018^{3}$. De forma similar, no Paraná, o programa Paraná Fala Idiomas $\left(\mathrm{PFI}^{4}\right)$ vem atuando desde 2013 na oferta de cursos de línguas estrangeiras para as comunidades acadêmicas de universidades estaduais, visando colaborar com o processo de internacionalização do ensino superior do Estado.

Neste estudo, busco identificar, à luz do interacionismo sociodiscursivo (BRONCKART, 1999; BRONCKART; MACHADO, 2004), as motivações para a criação do programa Paraná Fala Idiomas (PFI), bem como seus propósitos e os protagonistas colocados em evidência em seu texto de apresentação no website oficial da Superintendência Geral de Ciência, Tecnologia e Ensino Superior (SETI).

\footnotetext{
${ }^{2}$ Disponível em: isf.mec.gov.br. Acesso em: 14 out. 2019.

3 Disponível em: http://isf.mec.gov.br/pesquisas-e-relatorios/33-pesquisas-e-relatorios/199-relatorionacional. Acesso em: 14 out. 2019.

4 Disponível em: http://www.seti.pr.gov.br/ugf/programas/paranafalaidiomas/apresentacao. Acesso em: 18 nov. 2019.
} 
Primeiramente, discorro sobre conceitos referentes ao processo de internacionalização do ensino superior (KNIGHT, 2003; ALTBACH, 2006; DE WIT, 2011) e a políticas linguísticas (CALVET, 2007; SHOHAMY, 2006). Então, apresento a metodologia de análise empregada, realizando uma descrição de alguns aspectos teórico-metodológicos do interacionismo sociodiscursivo (ISD) segundo Bronckart (1999) e Bronckart e Machado (2004). Feito isso, passo à avaliação do contexto sociointeracional de produção do texto e, em seguida, realizo a análise da infraestrutura textual. Após analisar o texto com base em procedimentos linguístico-discursivos, realizo uma reinterpretação dos dados por meio de uma semântica do agir (BRONCKART; MACHADO, 2004) e, em seguida, teço as considerações finais.

\section{A INTERNACIONALIZAÇÃO DO ENSINO SUPERIOR}

De acordo com Altbach (2006), as universidades sempre estiveram inseridas em diversos contextos de âmbito global, sendo afetadas por circunstâncias para além de seus muros e até de seus países. Mais recentemente, no entanto, vem crescendo o interesse em compreender o impacto da globalização no ensino superior, além das realidades subjacentes ao processo de internacionalização buscado pelas universidades, segundo o autor. Para De Wit (2011), a globalização de nossas sociedades e economias tem ampliado a influência da competição e dos processos mercadológicos no modo como a internacionalização é implementada.

Na perspectiva de Altbach (2006), enquanto a globalização refere-se às amplas tendências econômicas, tecnológicas e científicas que afetam diretamente o ensino superior, a internacionalização inclui as políticas e programas específicos empreendidos por governos, sistemas acadêmicos e instituições, ou mesmo por departamentos ou instituições individuais para lidar com ou explorar a globalização. Uma definição amplamente aceita para o conceito de internacionalização é proposta por Knight (2003), segundo a qual a internacionalização seria o processo de integração das dimensões internacional, intercultural ou global nos propósitos, nas funções e na oferta do ensino superior, sendo a tais funções atribuídas as diversas ações relacionadas à tríade ensino, pesquisa e extensão.

Adicionalmente, De Wit (2011) ressalta que o discurso convencional referente à internacionalização do ensino superior considera uma abordagem baseada em um processo integral, voltada para a melhoria da qualidade do ensino superior, bem como das competências dos membros das comunidades acadêmicas. O autor acredita, no 
entanto, que a realidade é menos promissora, com base na percepção de que exista uma predominância de uma abordagem instrumental para a internacionalização, o que pode, segundo ele, levar a equívocos quanto ao seu fim.

Nesse sentido, o autor apresenta nove conceitos comumente atribuídos à internacionalização que considera, no entanto, equivocados, sendo eles: a ideia de que a internacionalização estaria voltada para 1) ofertar disciplinas em língua inglesa; 2) estudar ou morar no exterior; 3) ofertar disciplinas baseadas em conteúdos de teor internacional; 4) ter um alto número de alunos estrangeiros matriculados na IES; 5) ter um número mínimo de alunos estrangeiros matriculados na IES; 6) prescindir da avaliação de competências interculturais ou internacionais com base na crença de que poderiam ser desenvolvidas naturalmente durante o intercâmbio ou nas aulas com conteúdo internacional; 7) considerar que, quanto maior a quantidade de parcerias estabelecidas, mais internacionalizada será a IES; 8) que o ensino superior é internacional por natureza; e 9) entender a internacionalização como um fim em si mesmo. (DE WIT, 2011).

As atividades relacionadas ao processo de internacionalização demandam, em grande parte, o conhecimento de idiomas estrangeiros, os quais figuram com significativa relevância para diversas transações no mundo globalizado. No contexto da pesquisa, a língua inglesa, em especial, é amplamente utilizada como meio primordial de comunicação e disseminação do conhecimento, o que faz com que tenha papel importante nesse processo.

Segundo Shohamy (2006), enquanto as línguas são dinâmicas, pessoais, livres e vivas, sem limites definidos, sempre houve quem as tentasse controlar e manipular em nome de ideologias políticas, sociais, econômicas ou mesmo pessoais, acarretando que se tornassem instrumentos para demonstrar pertencimento a um determinado grupo. É nesse cenário que as políticas linguísticas encontram espaço.

O campo de intervenção das políticas linguísticas é constituído, segundo Calvet (2007), pela definição das diferenças entre duas situações sociolinguísticas distintas: uma inicial, avaliada como insatisfatória para o alcance de determinados objetivos, e outra desejável, na qual as chances de sucesso seriam maiores. Por outro lado, saber como passar de uma situação à outra ficaria a cargo do que o autor define como planejamento linguístico. 
O processo de internacionalização do ensino superior no Brasil tem contado com a implementação de políticas linguísticas tanto em âmbito nacional, como no caso do IsF, quanto estadual, a exemplo do PFI. Este estudo está voltado a compreender alguns aspectos referentes a uma política linguística local, o Paraná Fala Idiomas (PFI), no principal texto de divulgação do programa.

\section{METODOLOGIA DE ANÁLISE}

A análise adotada para este estudo foi conduzida a partir das seguintes perguntas norteadoras:

1. Que aspectos podem ser identificados como motivações para a implementação do programa PFI?

2. Que aspectos podem ser identificados como propósitos do programa?

3. Quais são os protagonistas colocados em evidência no texto analisado e que papéis são a eles atribuídos?

Para responder a essas perguntas, duas metodologias de análise do quadro teórico-metodológico do interacionismo sociodiscursivo (ISD) foram utilizadas de forma complementar. A primeira delas, proposta por Bronckart (1999), remete a um modelo global de produção e análise de texto, o qual considera que haja uma interdependência entre características da situação de produção do texto e características do texto em si. O segundo método de análise refere-se a uma expansão desse, proposto por Bronckart e Machado (2004), para analisar as formas do agir no discurso do trabalho educacional.

De acordo com o quadro teórico-epistemológico do interacionismo sociodiscursivo (ISD), é apenas por meio da análise de textos e discursos que a ação humana pode ser efetivamente avaliada e interpretada. Segundo Bronckart, é a situação de ação de linguagem que "designa as propriedades dos mundos formais (físico, social e subjetivo) que podem exercer influência sobre a produção textual.” (BRONCKART, 1999, p. 91). Tais condições, segundo o autor, podem ser divididas em situações de ação de linguagem externa e em situações de ação de linguagem interna ou efetiva. As primeiras se relacionam com as características dos mundos formais, tais como uma comunidade de observadores poderia descrever, enquanto as últimas, referem-se às representações sobre esses mesmos mundos, tais como um agente as interiorizou, sendo essa a situação que influi realmente sobre a produção de um texto empírico. (BRONCKART, 1999). 
O autor afirma, no entanto, que um pesquisador não tem acesso a essa situação de ação interna, o que faz com que possa formular apenas hipóteses relacionadas a elas com base na coleta de informações referentes à situação de ação externa. Além disso, segundo Bronckart (1999), é a partir de suas representações que um agente toma uma série de decisões, tais como: gênero de texto, tipos de discurso, sequências e mecanismos de textualização. $\mathrm{O}$ autor sustenta ainda, apoiando-se em Foucault e Bakhtin, que

a produção do discurso é, indissoluvelmente, trabalho psicológico e trabalho linguístico, que ela, portanto, é um objeto comum a essas duas disciplinas, ou ainda, que perde sua substância e sua significação próprias, quando é tratada abstraindo-se uma dessas duas abordagens. (BRONCKART, 1999, p. 148-149).

A fim de compreender como se dá a união desses dois tipos de trabalho, Bronckart (1999) elaborou uma proposta de análise de textos de grande relevância para o interacionismo sociodiscursivo, na qual este estudo apoiou-se para realizar o primeiro momento de análise dos dados. Essa concepção, conhecida como abordagem descendente de análise dos textos, ocorre segundo os seguintes grupos de procedimentos:

1. Análise do contexto sociointeracional mais amplo (levantamento de hipóteses sobre as representações do enunciador sobre o contexto de produção imediato);

2. Análise do texto propriamente dito:

a) O plano global do texto, os tipos de discurso e as sequências que constituem os tipos de discurso;

b) Os mecanismos de textualização que abrangem os mecanismos de coesão nominal, verbal e de conexão;

c) Os mecanismos enunciativos (detecção das vozes presentes no texto e de seus valores, além da detecção das modalizações e de seus valores para o levantamento dos posicionamentos do produtor em relação à atividade);

3. Detecção das funções sintático-semânticas das unidades linguísticas que representam os actantes postos em cena no e pelo texto (características do agir comunicacional: no plano motivacional, no plano da intencionalidade e no plano dos recursos para o agir) (BRONCKART, 1999). 
Adicionalmente, tendo em vista o contexto educacional presente no objeto de análise deste estudo, utilizo ainda algumas contribuições realizadas posteriormente por Bronckart e Machado (2004). A fim de compreender o trabalho do professor "tanto em relação ao seu agir concreto quanto em relação a alguns dos aspectos das representações que socialmente se constroem sobre ele" (BRONCKART; MACHADO, 2004, p. 135), os autores propõem uma metodologia de análise de textos sobre o trabalho educacional ou no decorrer desse trabalho. Para eles, é importante analisar os textos ou a rede discursiva que se constrói na e sobre uma determinada atividade em busca de uma melhor compreensão das ações desenvolvidas e do papel da linguagem no referido contexto.

À vista disso, Bronckart e Machado (2004) propõem primeiramente um grupo de procedimentos propriamente analítico, linguístico-discursivo, e outro interpretativo, inspirado no método de análise da "semântica do agir". O primeiro grupo de procedimentos está baseado no modelo de análise de textos proposto por Bronckart (1999) descrito acima, embora guarde semelhanças com procedimentos desenvolvidos por outros analistas de linguagem e/ou de discurso, segundo os autores. Esse grupo de procedimentos busca levantar informações sobre o contexto sociointeracional de produção dos textos, bem como a análise de características globais dos textos (suporte em que o texto é veiculado, sua configuração global, entre outros) e de aspectos da infraestrutura textual.

Quanto ao segundo grupo, Bronckart e Machado (2004) propõem reinterpretar as análises à luz de categorias de uma semântica do agir, segundo as quais

o termo agir designa o dado sob análise, isto é, as diferentes ocorrências de intervenções de seres humanos no mundo, enquanto os termos atividade e ação designam interpretações desse agir, coletivas e individuais respectivamente, e que mobilizam ou explicitam as dimensões motivacionais (razões de agir, retrospectivas) e intencionais (finalidades do agir, prospectivas), assim como os recursos sincronicamente disponíveis para os agentes. (BRONCKART; MACHADO, 2004, p. 154, grifos no texto original).

Neste estudo, analiso o texto de apresentação do programa Paraná Fala Idiomas (PFI), divulgado no website oficial da Superintendência Geral de Ciência, Tecnologia e Ensino Superior $(\mathrm{SETI})^{5}$. O objetivo do estudo é compreender as razões e motivações

\footnotetext{
5 Disponível em: http://www.seti.pr.gov.br/ugf/programas/paranafalaidiomas/apresentacao. Acesso em: 18 nov. 2019.
} 
que impulsionaram a criação do programa, suas finalidades, além de identificar os protagonistas colocados em evidência, bem como os papéis a eles atribuídos.

Para tanto, adoto os procedimentos de análise linguístico-discursivos propostos por Bronckart (1999) e Bronckart e Machado (2004) para compreender o contexto sociointeracional de produção do texto bem como sua infraestrutura textual. Feito isso, realizo uma reinterpretação dessa análise à luz de categorias de uma semântica do agir, conforme proposta por Bronckart e Machado (2004), por meio da qual busco compreender as razões e finalidades para a criação do programa PFI bem como os papéis atribuídos a cada actante ${ }^{6}$ nesse contexto.

\section{O CONTEXTO SOCIOINTERACIONAL DE PRODUÇÃO}

Bronckart (1999) define o contexto de produção dos textos como o "conjunto de parâmetros que podem exercer uma influência sobre a forma como um texto é organizado" (p. 93). Desse modo, a construção de conhecimentos do contexto sociointeracional de produção do texto analisado neste artigo se dá com base em informações levantadas a partir de um ambiente externo ao do texto em questão. Tendo isso em vista, a fim de compreender melhor o contexto socio-histórico em que o programa se encontra e assim buscar identificar o contexto sociointeracional de produção do texto, traço a seguir um breve panorama histórico do surgimento de políticas linguísticas voltadas para as universidades brasileiras na última década.

O processo de internacionalização do ensino superior brasileiro ganhou maior notoriedade nos últimos 10 anos, especialmente a partir da criação do programa do governo federal Ciência Sem Fronteiras (CsF), em 2011, com vistas a uma maior inserção de estudantes e pesquisadores brasileiros em universidades do exterior. No entanto, tão logo o programa foi implementado, um novo desafio emergiu da realidade dos pesquisadores brasileiros em intercâmbio internacional - a falta de proficiência em línguas estrangeiras, especialmente em inglês, apresentou-se como um fator limitante de aproveitamento dos cursos e do desenvolvimento acadêmico dos estudantes no exterior.

(ABREU-E-LIMA et al., 2016).

\footnotetext{
${ }^{6}$ Neste trabalho, utilizo a terminologia proposta por Bronckart e Machado (2004) com relação aos seres humanos postos em evidência nos textos analisados, sendo o termo actante utilizado para qualquer pessoa implicada no agir. Por outro lado, no plano interpretativo, os autores sugerem a utilização do termo ator "quando as formas textuais colocam esse actante como sendo a fonte de um processo e quando a ele são atribuídas capacidades, motivos e intenções". Quando, no entanto, essas formas não atribuem ao sujeito tais propriedades, os autores propõem a utilização do termo agente. (BRONCKART; MACHADO, 2004).
} 
Tal constatação deu origem ao surgimento de políticas linguísticas voltadas a suprir a necessidade de desenvolvimento de proficiência em línguas estrangeiras até então vista como insuficiente nos estudantes participantes do CsF. Dessa forma, o governo brasileiro, por intermédio do Ministério da Educação, instituiu, em 2012, o programa Inglês sem Fronteiras, cujo principal objetivo era "propiciar a formação e capacitação de alunos de graduação das instituições de educação superior para os exames linguísticos exigidos para o ingresso nas universidades anglófonas" (BRASIL, 2012, p. 1). Dois anos mais tarde, tal programa foi reformulado e ampliado para a oferta de cursos em outras línguas estrangeiras, de forma a atender um público-alvo mais abrangente, ocasião na qual passou a se chamar Idiomas sem Fronteiras (IsF). (BRASIL, 2014).

Em um primeiro momento, no entanto, o programa IsF contemplou apenas os alunos e pesquisadores das universidades federais, deixando uma lacuna expressiva ao não englobar os membros das comunidades acadêmicas das IES estaduais que porventura tivessem interesse no programa. A fim de suprir essa carência no Estado do Paraná, foi instituído, no ano de 2013, o programa Paraná Fala Inglês (PFI) com o apoio da Secretaria de Ciência, Tecnologia e Ensino Superior, recentemente renomeada Superintendência Geral de Ciência, Tecnologia e Ensino Superior (SETI), e da Unidade Gestora do Fundo Paraná (UGF), caracterizando-se como a primeira fase de um plano estratégico da SETI intitulado Paraná Fala Línguas Estrangeiras.

Tanto IsF quanto PFI foram criados como ações complementares às atividades do CsF, de onde tem sido possível observar que ações de políticas linguísticas vêm ocorrendo de forma atrelada a políticas de internacionalização. (MARSON; FURTOSO, 2015; GIMENEZ; PASSONI, 2016). Com relação ao PFI, especificamente, Marson e Furtoso (2015) afirmam que

o projeto Paraná Fala Inglês está inserido em um contexto sociohistórico de internacionalização do ensino superior brasileiro que reconhece a necessidade de implementação de políticas linguísticas como complemento para atingir os objetivos de mobilidade internacional. (MARSON; FURTOSO, 2015, p. 710).

Corroboro a afirmação das autoras, reconhecendo o programa Paraná Fala Idiomas $^{7}$, como um todo, no contexto socio-histórico da internacionalização do ensino

\footnotetext{
${ }^{7}$ O Programa Paraná Fala Idiomas engloba dois programas específicos - o Paraná Fala Inglês, o qual representou o primeiro passo da iniciativa, e o Paraná Fala Francês, instituído em 2017. O trabalho desenvolvido por Marson e Furtoso (2015) refere-se apenas ao programa de língua inglesa por ser anterior à inclusão da oferta de cursos em língua francesa. Considero que o contexto socio-histórico da
} 
superior brasileiro. Tendo isso em vista, busco identificar o contexto sociointeracional de produção do texto analisado neste artigo, investigando o lugar social onde é produzido, a posição social do emissor e do receptor e os objetivos da interação.

A partir da discussão realizada até aqui, infere-se que o texto de apresentação do programa, divulgado no website oficial da SETI, apresenta um enunciador na figura de um agente oficial do Paraná Fala Idiomas cujo discurso é voltado para um destinatário com interesse em informações relacionadas ao programa ou aos cursos por ele ofertados.

Quanto aos destinatários, identifico como possíveis interessados aqueles aos quais os cursos se dirigem, ou seja, estudantes, docentes e agentes universitários em busca de um aperfeiçoamento de suas competências linguísticas em línguas estrangeiras, especialmente se voltado para fins acadêmicos ou como capacitação para seu trabalho no processo de internacionalização das universidades. De certa forma, pode ser considerado também o público em geral interessado em obter informações sobre o programa como pertencente ao grupo ao qual o texto se destina.

Com relação aos objetivos da interação, é possível identificar como principais os de apresentar informações relacionadas ao PFI, descrevendo seus objetivos, instituições envolvidas e relatando as diferentes fases do programa. No entanto, de acordo com Bronckart (1999), os objetivos de um texto são teoricamente infinitos, não havendo, portanto, como criar uma lista exaustiva deles.

Tendo finalizado essa avaliação de cunho contextual, volto-me para a fase propriamente analítica dos textos, cuja primeira etapa encontra-se na observação de suas características mais globais.

\section{A INFRAESTRUTURA TEXTUAL}

Nesta seção, exponho a análise do texto referente à apresentação do programa Paraná Fala Idiomas (PFI) veiculado pelo website oficial da Superintendência Geral de Ciência, Tecnologia e Ensino Superior (SETI) ${ }^{8}$.

O plano global do texto permite identificar três subdivisões principais: primeiramente, é realizada a Apresentação geral do programa, disposta em quatro parágrafos; em seguida, é exposto o Objetivo Geral do PFI; por fim, os Objetivos

internacionalização do ensino superior possa ser atribuído, no entanto,ao programa Paraná Fala Idiomas como um todo.

${ }^{8}$ Disponível em: http://www.seti.pr.gov.br/ugf/programas/paranafalaidiomas/apresentacao Acesso em: 18 nov. 2019. 
Específicos são elencados por meio do uso de sete marcadores textuais, como pode ser observado na Figura 1.

Figura 1 - Imagem do texto de apresentação do PFI no website da SETI

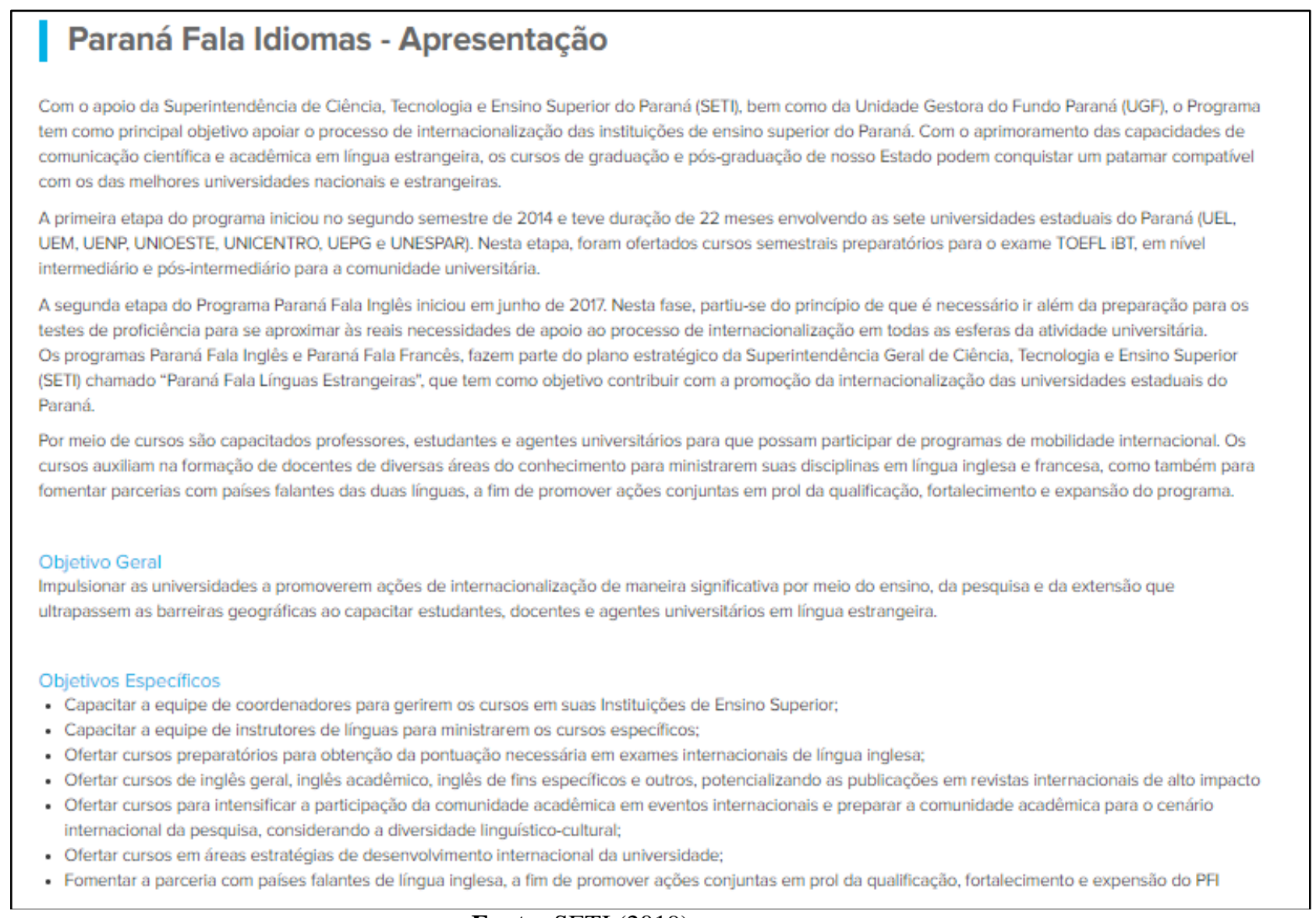

Fonte: SETI (2019).

Embora o título "Paraná Fala Idiomas - Apresentação" refira-se ao texto selecionado como um todo, uma análise inicial permite inferir que a primeira subdivisão teria por objetivo realizar uma apresentação geral do programa, enquanto as demais ficariam responsáveis por apresentar de forma mais detalhada os seus objetivos. Tendo isso em vista, o plano global do texto está configurado da seguinte forma:

Quadro 1 - Plano global do texto

\section{\begin{tabular}{l|l} 
Apresentação & Descrição do principal objetivo do programa
\end{tabular}}

(apoiar o processo de internacionalização das IES do Paraná)

Descrição de como se deu a primeira etapa

(oferta de cursos preparatórios para o exame TOEFL iBT ${ }^{9}$ )

Readequação da proposta na segunda etapa e reiteração do objetivo principal

\footnotetext{
${ }^{9}$ Test of English as a Foreign Language - Internet Based Test.
} 
REVISTA X, Curitiba, volume 14, n.6,p.66-86, 2019.

\begin{tabular}{|l|l|}
\hline \multirow{5}{*}{$\begin{array}{l}\text { (reconhecimento da necessidade de ir além da preparação para testes de } \\
\text { proficiência; identificação dos programas integrantes e reforço do objetivo } \\
\text { principal - contribuir com a promoção da internacionalização das } \\
\text { universidades estaduais do Paraná) } \\
\text { Introdução aos objetivos específicos } \\
\text { (capacitação de professores, estudantes e agentes universitários para o } \\
\text { processo de internacionalização das universidades) }\end{array}$} \\
\hline Objetivo geral & \multicolumn{2}{|l}{} \\
\hline Objetivos específicos &
\end{tabular}

Fonte: a autora.

A análise do plano global do texto permite observar que, embora o objetivo geral e os objetivos específicos do PFI sejam descritos em seções particulares, algumas finalidades são expostas ainda na seção de apresentação geral do programa, podendo-se identificar, inclusive, um encadeamento das mesmas, como no seguinte exemplo:

o Programa tem como principal objetivo apoiar o processo de internacionalização das instituições do ensino superior do Paraná. Com o aprimoramento das capacidades de comunicação científica e acadêmica em língua estrangeira, os cursos de graduação e pósgraduação de nosso Estado podem conquistar um patamar compatível com os das melhores universidades nacionais e estrangeiras. (SETI, 2019).

A partir desse excerto, é possível inferir que o aprimoramento das capacidades de comunicação científica e acadêmica em língua estrangeira, objetivo inicial do PFI, é visto como potencial estímulo para que os cursos de graduação e pós-graduação do Paraná possam conquistar um patamar compatível com os das melhores universidades nacionais e estrangeiras, o que apoiaria, por fim, o processo de internacionalização das IES do Paraná.

Além dessas, outras finalidades podem ser identificadas ainda na seção de apresentação inicial do programa, reafirmando constantemente seu objetivo principal - a promoção da internacionalização das IES estaduais do Paraná. O Quadro 2, abaixo, elenca tais finalidades em destaque.

Quadro 2 - Identificação de finalidades do programa na seção Apresentação [...] o Programa tem como principal objetivo apoiar o processo de internacionalização das instituições do ensino superior do Paraná. (Parágrafo 1)

Com o aprimoramento das capacidades de comunicação científica e acadêmica em língua estrangeira, os cursos de graduação e pós-graduação de nosso Estado podem conquistar um patamar compatível 
com os das melhores universidades nacionais e estrangeiras. (Parágrafo 2)

[...] é necessário ir além da preparação para os testes de proficiência para se aproximar às reais necessidades de apoio ao processo de internacionalização em todas as esferas da atividade universitária. (Parágrafo 3)

[...] que tem como objetivo contribuir com a promoção da internacionalização das universidades estaduais do Paraná. (Parágrafo 3)

Por meio de cursos são capacitados professores, estudantes e agentes universitários para que possam participar de programas de mobilidade internacional. (Parágrafo 4)

Os cursos auxiliam na formação de docentes de diversas áreas de conhecimento para ministrarem suas disciplinas em língua inglesa e francesa, como também para fomentar parcerias com países falantes das duas línguas, a fim de promover ações conjuntas em prol da qualificação, fortalecimento e expansão do programa. (Parágrafo 4)

Fonte: a autora.

A partir da seleção realizada e exposta no Quadro 2, podem ser identificadas como finalidades do programa diversas atividades relacionadas ao processo de internacionalização do ensino superior, foco principal das ações realizadas nessa iniciativa. Dentre tais atividades, destaco a capacitação de professores, estudantes $e$ agentes universitários para que possam participar de programas de mobilidade internacional, a capacitação de professores de diversas áreas de conhecimento para que possam ministrar suas disciplinas em língua inglesa e francesa, bem como para fomentar parcerias com países falantes desses idiomas, e o interesse em promover ações conjuntas em prol da qualificação, fortalecimento e expansão do programa.

A identificação dessas finalidades, encontradas ainda na seção inicial de apresentação do programa, permite confirmar a internacionalização do ensino superior das IES estaduais do Paraná como contexto de produção socio-histórico no qual o programa se encontra, conforme mencionado na análise do contexto sociointeracional de produção do texto.

Com relação aos tipos de discurso e às marcas enunciativas presentes no texto, pode-se identificar, inicialmente, um segmento de discurso teórico, no qual é apresentada logo de início a justificativa para a existência do programa - apoiar o processo de internacionalização das instituições do ensino superior do Paraná. Nesse segmento, encontra-se o único dêitico pessoal presente ao longo de todo o discurso sob análise (nosso Estado), o qual, embora seja insuficiente para que se revele de forma explícita a subjetividade do produtor do texto, permite estabelecer um discreto grau de proximidade entre o agente-produtor e o interlocutor. 
O texto passa, então, por um segmento narrativo que visa a descrever as duas primeiras fases do programa, sendo uma já acabada (primeira etapa do programa), e outra provavelmente em curso no momento de produção do texto, uma vez que esse não apresenta dados sobre sua conclusão (segunda etapa do Programa Paraná Fala Inglês). É nesse segmento que as universidades participantes são postas em evidência, embora apareçam apenas como actantes com papel instrumental no programa.

Ainda no segmento narrativo, encontrado no segundo e terceiro parágrafos do texto, é possível perceber uma mudança na natureza dos cursos ofertados da primeira para a segunda etapa. Tal mudança parece ter sido motivada por um determinante externo, o qual não é, no entanto, explicitado no texto em análise, como pode ser verificado em

partiu-se do princípio de que é necessário ir além da preparação para os testes de proficiência para se aproximar às reais necessidades de apoio ao processo de internacionalização em todas as esferas da atividade universitária. (SETI, 2019).

No excerto acima, a ocorrência da relação predicativa de valor deôntico em partiu-se do princípio de que é necessário ir além deixa o pressuposto de que os resultados obtidos durante a primeira fase do programa foram, de alguma forma, insuficientes para os objetivos inicialmente traçados.

Em pesquisa realizada sobre a primeira etapa do programa na Universidade Estadual de Londrina (UEL), Marson (2017) identificou algumas lacunas na forma como o PFI foi proposto naquele momento. Entre suas constatações estavam o fato de que, estando os cursos voltados apenas para a preparação para exames de proficiência em língua inglesa, as necessidades de alguns alunos do PFI, a exemplo dos agentes universitários, não foram atendidas, uma vez que tais cursos não se aplicavam ao trabalho por eles realizado nas IES. Constatações como essa, que porventura tenham sido verificadas ao longo da primeira etapa do programa em diferentes IES participantes, podem ter motivado as mudanças na oferta de cursos para a segunda etapa. A razão por trás de tal decisão é, no entanto, omitida pelo agente-produtor no texto analisado neste estudo.

O segmento narrativo é encontrado no segundo parágrafo e na primeira metade do terceiro parágrafo. A partir de então, retorna-se a um expor autônomo, o qual se estende até o fim da seção introdutória do texto, apresentando os diferentes programas que compõem a iniciativa - Paraná Fala Inglês e Paraná Fala Francês, reafirmando o 
objetivo principal do programa e finalizando com uma exposição de suas potenciais contribuições.

No último parágrafo da seção introdutória do texto, a exposição assertiva das contribuições do programa produz o efeito de uma pretensa objetividade no enunciado, com o uso de relações predicativas diretas garantindo um valor de verdade às declarações realizadas.

Por meio de cursos são capacitados professores, estudantes e agentes universitários para que possam participar de programas de mobilidade internacional. Os cursos auxiliam na formação de docentes de diversas áreas de conhecimento para ministrarem suas disciplinas em língua inglesa e francesa, como também para fomentar parcerias com países falantes das duas línguas, a fim de promover ações conjuntas em prol da qualificação, fortalecimento e expansão do programa. (SETI, 2019 - grifos da autora).

A análise do excerto acima permite considerar que é atribuída aos cursos ofertados pelo programa a faculdade de capacitar professores, estudantes e agentes universitários para uma candidatura a programas de mobilidade internacional (por meio de cursos são capacitados), além de dar suporte a professores de diversas áreas de conhecimento para que exerçam suas atividades docentes em línguas estrangeiras (os cursos auxiliam na formação).

A intencionalidade do agente-produtor pode ser inferida a partir do uso de locuções, a exemplo das ocorrências grifadas no excerto acima, em que para que e a fim de indicam a intenção de que os cursos ofertados pelo programa contribuam para o processo de mobilidade acadêmica e para a promoção de ações conjuntas com universidades do exterior.

Ainda com relação ao excerto acima, nota-se que o programa Paraná Fala Idiomas, inicialmente apresentado como meio para fortalecer o processo de internacionalização das IES estaduais, passa a ser apontado também como fim de sua própria iniciativa, uma vez que a qualificação, o fortalecimento e a expansão do programa figuram igualmente como objetivos de suas próprias ações.

De modo mais particular, as outras duas subdivisões do texto, intituladas Objetivo Geral e Objetivos Específicos, apresentam uma série de finalidades atribuídas à criação do programa PFI, sendo a principal delas

Impulsionar as universidades a promoverem ações de internacionalização de maneira significativa por meio do ensino, da pesquisa e da extensão que ultrapassem as barreiras geográficas ao 
capacitar estudantes, docentes e agentes universitários em língua estrangeira. (SETI, 2019).

O excerto acima, referente ao objetivo geral do PFI, reafirma a internacionalização das IES estaduais do Paraná como principal foco do programa, o que também pode ser observado na análise do texto encontrado na subseção objetivos específicos, como segue:

1. Capacitar a equipe de coordenadores para gerirem os cursos em suas Instituições de Ensino Superior;

2. Capacitar a equipe de instrutores de línguas para ministrarem os cursos específicos;

3. Ofertar cursos preparatórios para obtenção da pontuação necessária em exames internacionais de língua inglesa;

4. Ofertar cursos de inglês geral, inglês acadêmico, inglês de fins específicos e outros, potencializando as publicações em revistas internacionais de alto impacto;

5. Ofertar cursos para intensificar a participação da comunidade acadêmica em eventos internacionais e preparar a comunidade acadêmica para o cenário internacional da pesquisa, considerando a diversidade linguístico-cultural;

6. Ofertar cursos em áreas estratégias de desenvolvimento internacional da universidade;

7. Fomentar a parceria com países falantes de língua inglesa, a fim de promover ações conjuntas em prol da qualificação, fortalecimento e expensão (sic) do PFI.

Fonte: SETI (2018b).

Inicialmente, a análise do excerto acima permite inferir que, dentre os objetivos específicos traçados, houve uma preocupação com a necessidade de se capacitar as equipes gestora e docente para suas atividades particulares no programa. Isso pode ter emergido do fato de que o PFI apresenta um formato relativamente novo, voltado para o ensino de línguas para contextos específicos, com vistas à internacionalização do ensino superior e, portanto, ainda pouco explorado.

Além disso, o detalhamento dos objetivos do programa, encontrado na subseção Objetivos Específicos, permite identificar uma série de finalidades voltada para o processo de internacionalização do ensino superior, cuja contribuição seria dada a partir da oferta de cursos de inglês capazes de colaborar com a obtenção da pontuação necessária em exames internacionais de língua inglesa, potencializar as publicações em revistas internacionais de alto impacto, intensificar a participação da comunidade acadêmica em eventos internacionais, preparar a comunidade acadêmica para o cenário internacional da pesquisa ou mesmo fomentar a parceria com países falantes de língua inglesa. 
REVISTA X, Curitiba, volume 14, n.6,p.66-86, 2019.

Diferentemente da parte introdutória do texto analisado, na subseção Objetivos Específicos ocorre um apagamento das contribuições esperadas por meio do programa Paraná Fala Francês, com uma intensificação das finalidades atribuídas às contribuições advindas da aprendizagem específica de língua inglesa para as comunidades acadêmicas beneficiadas com o PFI.

A esse respeito, é importante ressaltar que a língua inglesa é amplamente reconhecida como idioma hegemônico no mundo acadêmico. Segundo Altbach (2006), o inglês é não apenas o idioma mais estudado, mas também a segunda língua mais usada em diversos países. A maioria das revistas científicas em circulação em âmbito internacional prioriza o uso da língua inglesa para disseminação do conhecimento. Essa hegemonia pode ser ainda identificada na alta valorização de professores universitários com publicações em revistas científicas de impacto internacional, especialmente quando em língua inglesa, na priorização por esse idioma em páginas da Internet voltadas para a ciência e bolsas de estudo, além de a língua inglesa figurar como idioma oficial dos países mais buscados pela maioria dos estudantes em mobilidade internacional.

Com relação ao texto analisado neste estudo, no entanto, os motivos por trás da decisão por priorizar as contribuições esperadas a partir dos cursos em língua inglesa do PFI na seção Objetivos Específicos não puderam ser identificados.

Quanto aos principais protagonistas agentivizados no texto, é possível identificar os seguintes: a Superintendência Geral de Ciência, Tecnologia e Ensino Superior do Paraná (SETI), a Unidade Gestora do Fundo Paraná (UGF), o Programa Paraná Fala Idiomas, os cursos de graduação e pós-graduação de nosso Estado, as sete universidades estaduais do Paraná (UEL, UEM, UENP, UNIOESTE, UNICENTRO, UEPG e UNESPAR $)^{10}$, os cursos ofertados pelo programa, bem como a comunidade universitária/acadêmica, os programas Paraná Fala Inglês e Paraná Fala Francês, o plano estratégico da SETI "Paraná Fala Línguas Estrangeiras", bem como os países falantes de língua inglesa e francesa. Além desses, figuram ainda como protagonistas postos em evidência nas duas seções voltadas para a descrição dos objetivos do programa, a equipe de coordenadores das IES e os instrutores de idiomas. Uma compreensão mais detalhada da participação de tais protagonistas será buscada na próxima seção.

\footnotetext{
${ }^{10}$ Universidade Estadual de Londrina (UEL), Universidade Estadual de Maringá (UEM), Universidade Estadual do Norte do Paraná (UENP), Universidade Estadual do Oeste do Paraná (UNIOESTE), Universidade Estadual do Centro-Oeste do Paraná (UNICENTRO), Universidade Estadual de Ponta Grossa (UEPG) e Universidade Estadual do Paraná (UNESPAR).
} 
REVISTA X, Curitiba, volume 14, n.6,p.66-86, 2019.

\section{UMA REINTERPRETAÇÃO}

Com o intuito de aprofundar a análise aqui realizada, passo, agora, a uma reinterpretação dos resultados obtidos, até o momento, à luz de categorias de uma semântica do agir, de acordo com a proposta de Bron

ckart e Machado (2004). Para tanto, farei uso das noções terminológicas por eles empregadas conforme apresento os dados reinterpretados. Isso posto, foi possível identificar as seguintes categorias no texto analisado:

1. Quanto aos protagonistas colocados em evidência no texto e seus papéis sintático-semânticos ${ }^{11}$, figuram:

- a SETI, a UGF e as sete universidades estaduais do Paraná com papel instrumental, ou seja, contribuem para que o processo dinâmico do programa aconteça (sendo a SETI e a UGF os apoiadores do programa, enquanto as Universidades do Estado do Paraná são apresentadas no texto analisado como agentes envolvidos no processo);

- os cursos de graduação e pós-graduação de nosso Estado, além da comunidade universitária/acadêmica com papel de beneficiários das atividades do programa (sendo a esses cursos conferido o potencial de conquistar um patamar compatível com os das melhores universidades nacionais e estrangeiras, e aos professores, estudantes e agentes universitários, a possibilidade de participar de programas de mobilidade internacional, entre outros);

- os países falantes de língua inglesa e francesa com papel factivo, ou seja, de estado ou resultado final de uma ação, figurando as parcerias com esses entre as finalidades do programa;

- a equipe de coordenadores e a equipe de instrutores de línguas do programa com papel beneficiário, tendo em vista receberem capacitação para que possam atuar em suas respectivas atividades; ${ }^{12}$

\footnotetext{
${ }^{11}$ A classificação dos sujeitos e de seus papéis sintático-semânticos aqui utilizada é baseada em Bronckart e Machado (2004) e, segundo os autores, inspirada em Fillmore (1975).

${ }^{12}$ Pode-se dizer, até certo ponto, que aos coordenadores e instrutores de idiomas também é concedido um papel agentivo no que se refere às ações específicas de sua competência (gerir os cursos em suas Instituições de Ensino Superior e ministrar os cursos específicos). Tais ocorrências não permitem, no entanto, diferenciar o papel desses sujeitos entre agentes e atores nos textos sob análise neste artigo. A esse respeito, ressalto que em outra pesquisa de minha autoria (em andamento) tenho buscado compreender os papéis dos coordenadores e instrutores de idiomas desse programa em uma das universidades participantes.
} 
REVISTA X, Curitiba, volume 14, n.6, p. 66-86, 2019.

- o Programa PFI e os cursos por ele ofertados com papel atributivo, sendo a eles conferidas capacidades de contribuição para que as finalidades relacionadas ao processo de internacionalização das IES estaduais ocorram;

2. Quanto ao agir, o texto analisado apresenta, prioritariamente, o Programa (e, por vezes, os seus cursos) como o verdadeiro ator no processo de capacitação de profissionais (coordenadores e instrutores de idiomas), da comunidade acadêmica (por meio de seus cursos) e como potencial incentivador do processo de internacionalização das IES do Paraná.

3. No plano motivacional, é possível inferir que as mudanças introduzidas na segunda etapa do programa parecem ter sido estabelecidas a partir de um determinante externo, omitido no texto. No entanto, não puderam ser identificados motivos para o agir no texto analisado. A partir disso, depreende-se que as motivações para a criação do programa estejam externas ao texto, podendo-se inferir que tenham alguma relação com as necessidades de formação em línguas estrangeiras dos pesquisadores interessados em programas de mobilidade acadêmica e/ou para produção e disseminação do conhecimento, conforme mencionado anteriormente na análise do contexto de produção do texto analisado.

4. Por outro lado, no plano da intencionalidade, foram identificadas diversas finalidades apresentadas como objetivos do programa, a maior parte delas voltada para o incentivo ao processo de internacionalização do ensino superior das universidades estaduais do Paraná, conforme verificado no Quadro 2. Além disso, atividades como fomentar parcerias com países falantes das duas línguas (inglesa e francesa) deixam o pressuposto de que se refiram às intenções do agente-produtor, ainda que esse não esteja subjetivado no texto analisado.

\section{CONSIDERAÇÕES FINAIS}

Por meio da análise do texto de apresentação do programa Paraná Fala Idiomas, divulgado em sua página oficial no website da SETI, é possível inferir que o processo de internacionalização do Ensino Superior das universidades estaduais do Paraná está intimamente ligado à criação do programa, o que pode ser compreendido tanto no plano motivacional quanto no plano da intencionalidade do discurso analisado.

A análise do contexto sociointeracional permite interpretar que o texto se dirige a um grupo específico de destinatários - estudantes, docentes e agentes universitários, 
REVISTA X, Curitiba, volume 14, n.6,p.66-86, 2019.

em busca de aperfeiçoamento de suas competências linguísticas em idiomas estrangeiros para fins acadêmicos, de mobilidade internacional ou para melhoria de seu trabalho no processo de internacionalização das IES de que fazem parte.

Além disso, o estudo do plano global do texto possibilita o reconhecimento de que o discurso analisado tenha como principal objetivo justificar a existência do programa Paraná Fala Idiomas a partir das finalidades a ele atribuídas, ressaltando, com isso, suas iminentes contribuições. O processo de internacionalização das universidades estaduais do Paraná é posto em evidência nas mais variadas formas, sendo ao PFI e aos cursos por ele ofertados atribuído o potencial de capacitar a comunidade acadêmica para que possa participar de programas de mobilidade internacional, potencializar as publicações em revistas de alto impacto internacional, entre outros.

De modo similar, essas e outras finalidades, voltadas para o processo de internacionalização, permeiam o plano intencional do discurso analisado de forma bastante assertiva. Por outro lado, o texto não permite compreender de que forma essa ação extensionista confere benefícios à comunidade fora dos muros das universidades.

Tendo em vista que o texto analisado é destinado a fornecer informações sobre o PFI, justificando a iniciativa e buscando atrair novos alunos, é possível reconhecer que o próprio Programa (ou seus cursos) figure $(\mathrm{m})$ como o(s) protagonista(s) com papel principal no processo, sendo a ele(s) atribuídas as capacidades de contribuir para a internacionalização das IES estaduais do Paraná, de capacitação dos profissionais atuantes no programa, entre outras. Para que se possa compreender em detalhes esse processo dinâmico e de que forma se dá a participação de cada protagonista identificado, no entanto, outras investigações seriam necessárias.

\section{REFERÊNCIAS}

ABREU-E-LIMA, D.; FILHO, W.; BARBOSA, W.; BLUM, A. O Programa Inglês sem Fronteiras e a política de incentivo à internacionalização do ensino superior brasileiro. In: SARMENTO, S.; ABREU-E-LIMA, D.; FILHO, W. (Org.). Do Inglês sem Fronteiras ao Idiomas sem Fronteiras: A construção de uma política linguística para a internacionalização. Belo Horizonte: Editora UFMG, 2016, p. 19-46.

BRASIL, Ministério da Educação. Portaria $n^{\circ} 1.466$, de 18 de dezembro de 2012. Disponível em: http://isf.mec.gov.br/images/pdf/portaria_normativa_1466_2012.pdf Acesso em: 08 ago. 2018.

BRASIL, Ministério da Educação. Portaria $n^{\circ}$ 973, de 14 de novembro de 2014. Disponível em: http://isf.mec.gov.br/images/pdf/novembro/Portaria_973_Idiomas_sem_ Fronteiras.pdf Acesso em: 08 ago. 2018. 
BRONCKART, J.; MACHADO, A. Procedimentos de análise de textos sobre o trabalho educacional. In: MACHADO, A. O ensino como trabalho: uma abordagem discursiva. Londrina: Eduel, 2004, p. 131-163.

BRONCKART, J. Atividade de linguagem, textos e discursos: por um sóciointeracionismo-discursivo. Trad. Anna Rachel Machado, Péricles Cunha. São Paulo: EDUC, 1999.

CALVET, L. As políticas linguísticas. São Paulo: Parábola, 2007.

DE WIT, H. Internationalization of Higher Education: nine misconceptions. International Higher Education, n. 64, p. 1-6, 2015.

GIMENEZ, T.; PASSONI, T. Políticas linguísticas e suas consequências não planejadas: o programa "Inglês Sem Fronteiras" e suas repercussões nos cursos de Letras. Calidoscópio, São Leopoldo, v. 14, 2016, p. 115-126.

IDIOMAS SEM FRONTEIRAS. Relatório nacional do Programa Idiomas sem Fronteiras. Disponível em: http://isf.mec.gov.br/historico-botoes/pesquisas-e-relatorios /33-pesquisas-e-relatorios/199-relatorio-nacional. Acesso em: 14 out. 2019.

KNIGHT, J. Updating the definition of Internationalization. International Higher Education. The Boston College Center for International Higher Education. Boston, n. 33, p. 2-3, 2003.

MARSON, M. Ensino de inglês e a internacionalização do ensino superior: percepções sobre o Programa "Paraná Fala Inglês" na UEL. 119f. Dissertação (Mestrado em Estudos da Linguagem) - Universidade Estadual de Londrina, 2017.

SARMENTO, S.; ABREU-E-LIMA, D.; FILHO, W. (Org.). Do Inglês sem Fronteiras ao Idiomas sem Fronteiras: A construção de uma política linguística para a internacionalização. Belo Horizonte: Editora UFMG, 2016.

SETI. Paraná Fala Idiomas. Site oficial. 2019. Disponível em: http://www.seti.pr. gov.br/ugf/programas/paranafalaidiomas/apresentacao Acesso em: 18 nov. 2019.

SHOHAMY, E. Language Policy: hidden agendas and new approaches. London: Routledge, 2006. 